\title{
IS THERE A DEVELOPMENTAL DIFFERENCE IN RECOGNIZING HARM THROUGH ACTION AND INACTION (COMMISSION AND OMISSION) BASED ON FIRST-ORDER MENTAL STATES?
}

\author{
Hajimu HAYASHI
}

Okayama University, Japan

\begin{abstract}
The aim of this study is to investigate whether there is a developmental difference in recognizing acts of harm through action and inaction (commission and omission). Thirty-nine children who were 4- to 6-year-olds judged tasks with acts of commission or acts of omission based on first-order mental states. Participants were more likely to give correct responses to mental state questions and incorrect ones to moral judgment questions than the reverse pattern. However, the difference between commissions or omissions did not significantly affect the correct responses in any age group. These results suggest that there are no developmental differences in recognizing acts of commissions and omissions based on the understanding of mental states.
\end{abstract}

Key words: harm through action (commission), harm through inaction (omission), first-order mental states, young children

There are generally two kinds of bad acts: commission and omission. The former is the harm through action or doing something (e.g., breaking things that are important to others with a stick) and the latter is the harm through inaction or doing nothing (e.g., allowing things that are important to others to be lost). Previous studies for adults have shown omission bias, which denotes the tendency of people to judge acts of commission as morally worse than equivalent omission when intentions and outcomes are held constant between them or even between a harmful commission and a more harmful omission (e.g., Haidt \& Baron, 1996; Ritov \& Baron, 1990; Spranca, Minsk, \& Baron, 1991). Omission bias is found in children as well as in adults (Baron, Granato, Spranca, \& Teubal, 1993). Even though these studies have shown that there is a difference in the degree of moral judgments in human cognition between acts of commission and omission, little is known whether there are developmental differences in moral judgments about commissions and omissions.

Piaget (1932) first demonstrated that only children over the age of 7 years made moral judgments based on the mental states of the actors. Subsequent studies, however, have shown that younger children can evaluate acts on the basis of mental states such as

I would like to thank the teachers at Heian Jogakuin St. Agnes Kindergarten in Osaka, Japan. This research was supported by a Research Fellowship of the Japan Society for the Promotion of Science for Young Scientists (No. 4477).

Correspondence regarding this article should be addressed to Hajimu Hayashi at Department of Educational Psychology, Graduate School of Education, Okayama University, 3-1-1, Tsushima-naka, Kitaku, Okayama, 700-8530, Japan (e-mail: hajimu@cc.okayama-u.ac.jp). 
intention (e.g., Farnill, 1974; Karniol, 1978; Keasey, 1977; Nelson, 1980; Nelson-Le Gall, 1985). Theory of mind studies also have shown that young children can understand firstorder mental states (e.g., Goushiki, 2000; Wellman, Cross, \& Watson, 2001) and that moral judgments depend on a consideration of mental states (e.g., Baird \& Astington, 2004) $)^{1}$

Thus, to correctly recognize whether a person's act is bad, it is necessary to examine his/her mental states. As described above, a large number of developmental studies have focused on the role of intention in moral judgments. On the other hand, studies are scarce about moral judgments based on other mental states such as knowledge and ignorance, which are also significant for moral reasoning because they connect the foreseeability of outcomes more directly. When a bad outcome occurs due to a person's action or inaction, we usually judge that such cases, in which he/she knew an important fact that could have helped him/her foresee the bad outcome, are morally worse than cases where he/she did not know the fact.

Mant and Perner (1988) compared the above two cases that required an understanding of first-order mental states regarding knowledge and ignorance, and showed that children up to the age of 9 years judged both protagonists were equally reprehensible for their inaction. Yuill and Perner (1987) also compared two cases that required the understanding of second-order mental states and reported that there was a sharp increase at about the age of 8 or 9 years in making responsibility attribution for actions. However, the main purpose was to examine children's understanding of commitments related to making promises, (Mant \& Perner, 1988), and the traffic rules of mutual trust based on second-order mental states attribution (Yuill \& Perner, 1987). Furthermore, theory of mind studies have shown that most children understand first-order mental states from about the age of 4 to 5 years (e.g., Wellman et al., 2001) and secondorder mental states form about the age of 6 to 7 years (e.g., Perner \& Wimmer, 1985). Hence, their task stories were not appropriate for examinig children's understanding of commissions and omissions.

Hayashi (2007) has used the similar method involving two types of acts, commissions and omissions, and two levels of mental states, first-order and second-order, with 7- to 11-year-old children. The tasks were less complex than the ones in Yuill and Perner (1987) and Mant and Perner (1988). Although 7-year-olds considered only firstorder mental states, the results showed that for both types of acts most of these children judged actors who knew an important fact to be morally worse than actors who did not know it. This result indicated that even at the age of 7 years, children could recognize acts of omission as well as acts of commission based on first-order mental states. Hence, we must examine whether a time lag exists in recognizing the difference between commission and omission related to first-order mental states among children younger than the age of 6 years.

To summarize, the main purpose of the present study is to examine whether a

\footnotetext{
${ }^{1}$ Human beings understand not only mental states such as knowledge or beliefs, but also complex mental states which have embedded structures such as beliefs about knowledge. In theory of mind research, these two types are called first-order mental states and second-order mental states, respectively. (e.g., Perner \& Wimmer, 1985).
} 
developmental difference exists in children's ability to recognize acts of commission and omission. If difference exists in the degree of difficulty in recognizing commission and omission, bad outcomes related to inaction are probably recognized at a different age from those related to action. On the contrary, if there is no such difference, then these two situations should be recognized at about the same age. The other purpose is to check that children's moral judgments of both types of acts require their understanding of mental states.

\section{METHOD}

\section{Participants}

Forty-one Japanese children participated in this experiment. Data from two children were excluded because of their failure to pay attention. The sample consisted of 124 -year-olds ( 6 boys and 6 girls; mean age 4:6 years; range 4:3-4:11), 16 5-year-olds ( 9 boys and 7 girls; mean age 5:6 years; range 5:0-5:11), and 11 6year-olds (6 boys and 5 girls; mean age 6:3 years; range 6:0-6:7). All attended kindergarten in the Osaka area, which is the typical urban area in Japan.

\section{Tasks}

The two tasks consisted of two types of acts (action or inaction). Both tasks had two similar stories, as in the methods used by Piaget (1932), Mant and Perner (1988), Hayashi (2007) etc. In both stories, a boy did something (in the case of the action task) or did nothing (in the case of the inaction task), and then something bad happened to a girl. The only difference between the two stories in each task was the boys' first-order mental states. In one story, the boy does not know an important fact that could help him foresee the bad outcome; in the other story, the boy knows the important fact. When adults understand the boys' mental states, they should usually judge that the second boy was worse. In the present study, therefore, this response is defined as situations where participants recognize commission (in the case of the action task) or omission (in the case of the inaction task).

The action (or inaction) task was as follows: In one story, a girl puts a white paper (or a beautiful hat) on the floor (or on a bench) and leaves. While the girl is away, a boy comes in and scribbles on the paper (or a boy allows the hat to be blown off the bench by a wind) and goes away. The girl comes back and finds that the paper has been scribbled on (or that the hat is lost) and feels sad.

The other story was identical except for the following: Before the girl leaves, the boy comes and asks the girl, "Is this your paper (or your hat)?" The girl replies, "Yes, it is." The rest of the story line was the same, namely, the boy scribbles on the paper (or, the boy allows the hat to be blown off the bench by a wind) and goes away. The girl comes back and finds that the paper has been scribbled on (or that the hat is lost) and feels sad.

The following four questions were used: control, mental state, moral judgment, and justification.

The control questions verified understanding of tasks by asking about a central fact in each story and understanding first-order mental states of the characters was not needed: "One of the two stories is that the boy met and talked with the girl and the other is that he did not meet and talk with her. Which is the story that he met and talked (or did not meet and talk) with her?" The experimenter, who was male and around thirty years old, pointed to a picture of a boy on the left and said, "Is it this boy?" Following this, the experimenter pointed to a picture of a boy on the right and said, "Or, is it this boy?"

The mental state questions stated: "In one story, 'The boy knew that the paper (or the hat) belonged to the girl' and in the other, "the boy did not know that the paper (or the hat) belonged to the girl." The participants were asked the following two questions. "Which boy knew (or did not know) that the paper (or the hat) belonged to the girl?" The experimenter pointed to a picture of a boy on the left and said, "Is it this boy?" Following this, the experimenter pointed to a picture of a boy on the right and said, "Or, is it this boy?"

The moral judgment questions asked: "Which boy is worse?" The experimenter pointed to a picture of a boy on the left and said, "Is it this boy?" Following this, the experimenter pointed to a picture of a boy on the right and said, "Or, is it this boy?" Then, the experimenter said, "Or, are both boys about equally bad?" 
In the present study, based on Hayashi (2007) and considering standard adult judgments, the only correct answer was defined as the case where participants judged that the boy who knew the important fact that could have helped him foresee the bad outcome was worse. Here, the important fact means that the paper (or the hat) belonged to the girl. The other two choices were defined as wrong answers.

The justification questions asked: "Why did you think so?" and requested participants to support their choice for the moral judgment questions.

\section{Procedure}

All participants were tested individually. To familiarize them with the method of choosing one of three choices for the moral judgment questions, we prepared three practice tasks before the main session. In each task, the experimenter (the author of the present study) showed two circles on a SONY VAIO laptop computer with a 15.4 inch screen. In the first task, there was a big circle on the left side and a small circle on the right, which were obviously of different sizes. In the second task, there was a small circle on the left and a big circle on the right. In the third task, there was a circle on the left and a same sized circle on the right. In each task, after presenting both circles, participants were asked "Which circle is bigger?" The experimenter pointed to the circle on the left and said, "Is it this circle?" Following this, the experimenter pointed to the circle on the right and said, "Or, is it this circle?" Then, the experimenter said, "Or, are both circles about the same size?" The order of the three tasks was counterbalanced. If participants gave wrong answers, they were told the correct answer and then given the same task after the three tasks were presented. All participants gave correct answers for the two tasks in which one circle was bigger than the other circle. A few participants gave wrong responses for the task in which the two circles were the same size, but all gave correct responses the second time.

After the practice session, the experimenter told the stories by showing one picture at a time for each task by using Microsoft PowerPoint. Each story in each task involved six cartoon-style pictures. After telling the two stories in each task, two groups of six consecutive pictures were shown side by side. These were carried out to reduce the information-processing load in the present method lower than that in the similar method of the previous studies such as Piaget (1932).

All tasks ended with the series of questions: the control question, the mental state question, the moral judgment question, and finally, justification question. If participants gave wrong answers to the control question, they were told the two stories again and then asked the control question again. The order of the two tasks and the two stories in each task was counterbalanced.

\section{RESULTS}

\section{Preliminary Analysis}

Four participants in the action task and four others in the inaction task were told the two stories again, because they gave wrong answers in the control question, but all of them gave correct answers the second time. Preliminary analysis showed no significant difference between the presentation order of the two tasks and by gender in the performance of each task. Therefore the data for these were combined for main analysis.

\section{Mental State Questions}

Table 1 shows the frequencies and the percentages of correct answers to the mental state questions. A chi-square test was used to determine the differences in the percentages of correct answers between age groups for each task. Multiple comparison tests using Ryan's method were performed to examine pairwise comparisons. Age groups differed significantly in the percentage of correct answers for the action task $\left(\chi^{2}(2)=9.78, p<.01\right)$ and for the inaction task, $\left(\chi^{2}(2)=6.20, p<.05\right)$. Pairwise comparisons indicated that 6 year-olds did significantly better than 4 - and 5-year-olds for the action task, and that 6 - 
Table 1. Correct and Wrong Responses to the Mental State Questions and Moral Judgment Questions

\begin{tabular}{|c|c|c|c|c|c|c|c|c|}
\hline \multirow{3}{*}{$\begin{array}{l}\text { Act } \\
\text { type }\end{array}$} & \multirow{3}{*}{$\begin{array}{l}\text { Age } \\
\text { group }\end{array}$} & \multicolumn{3}{|c|}{ Mental state question } & \multicolumn{4}{|c|}{ Moral judgment question } \\
\hline & & \multirow[b]{2}{*}{ Correct } & \multirow[b]{2}{*}{ Wrong } & \multirow[b]{2}{*}{ Total } & \multirow[b]{2}{*}{ Correct } & \multicolumn{2}{|c|}{ Wrong } & \multirow[b]{2}{*}{ Total } \\
\hline & & & & & & Opposite & $\begin{array}{c}\text { Both boys are } \\
\text { about equally bad }\end{array}$ & \\
\hline \multirow[t]{4}{*}{ Action } & 4 years & $5(41.7 \%)$ & $7(58.3 \%)$ & 12 & $2(16.7 \%)$ & $5(41.6 \%)$ & $5(41.6 \%)$ & 12 \\
\hline & 5 years & $8(50.0 \%)$ & $8(50.0 \%)$ & 16 & $5(31.3 \%)$ & $3(18.8 \%)$ & $8(50.0 \%)$ & 16 \\
\hline & 6 years & $11(100 \%)$ & $0(0 \%)$ & 11 & $5(45.5 \%)$ & $1(9.1 \%)$ & $5(45.5 \%)$ & 11 \\
\hline & Total & 24 & 15 & 39 & 12 & 9 & 18 & 39 \\
\hline \multirow[t]{4}{*}{ Inaction } & 4 years & $5(41.7 \%)$ & $7(58.3 \%)$ & 12 & $3(25.0 \%)$ & $5(41.6 \%)$ & $4(33.3 \%)$ & 12 \\
\hline & 5 years & $9(56.3 \%)$ & $7(43.8 \%)$ & 16 & $6(37.5 \%)$ & $4(25.0 \%)$ & $6(37.5 \%)$ & 16 \\
\hline & 6 years & $10(90.9 \%)$ & $1(9.1 \%)$ & 11 & $4(36.4 \%)$ & $2(18.2 \%)$ & $5(45.5 \%)$ & 11 \\
\hline & Total & 24 & 15 & 39 & 13 & 11 & 15 & 39 \\
\hline
\end{tabular}

year-olds did significantly better than 4-year-olds for the inaction task. A series of McNemar's tests revealed no significant differences in the percentages of correct answers between the two tasks for each of the age groups; $\chi^{2}(1)=1.00, n s$, for 4-year-olds; $\chi^{2}(1)=0.14, n s$, for 5-year-olds; $\chi^{2}(1)=0.33, n s$, for 6-year-olds.

\section{Moral Judgment Questions}

Table 1 shows the frequencies and the percentages of correct answers to the moral judgment questions. The percentages tended to increase with age, but chi-square tests revealed that age groups did not differ significantly in the percentage of correct answers for the action task $\left(\chi^{2}(2)=2.24, n s\right)$ and for the inaction task $\left(\chi^{2}(2)=0.55, n s\right)$. A series of McNemar's tests revealed no significant differences in the percentages of correct answers between the two tasks for each of the age groups; $\chi^{2}(1)=0.00, n s$, for 4-yearolds; $\chi^{2}(1)=0.33, n s$, for 5 -year-olds; $\chi^{2}(1)=1.00, n s$, for 6-year-olds.

There were two wrong answers among the three choices in answering the moral judgment questions: the case where participants judged that the boy who did not know the paper (or the hat) belonged to the girl was worse, which means that participants chose the opposite, and the case where participants judged that both boys were about equally bad. The percentages of the latter among the two wrong answers were $66.7 \%$ (18/27) for the action task and $57.7 \%(15 / 26)$ for the inaction task.

\section{Pattern of Mental State Questions and Moral Judgment Questions}

Table 2 shows the pattern of correct and wrong responses to the two questions for the two tasks. In the action task, 15 participants gave correct answers to the mental state question but made wrong answers to the moral judgment question, whereas only three showed the reverse pattern (McNemar's test: $\chi^{2}(1)=8.00, p<.01$ ). In the inaction task, 
Table 2. Responses to the Mental State Questions and the Moral Judgment Questions

\begin{tabular}{cccccc}
\hline \multirow{3}{*}{ Act type } & & \multicolumn{4}{c}{ Moral judgment question } \\
\cline { 3 - 5 } & $\begin{array}{c}\text { Mental state } \\
\text { question }\end{array}$ & Correct & \multicolumn{2}{c}{ Wrong } & \multirow{2}{*}{ Total } \\
\cline { 3 - 5 } & & & Opposite & $\begin{array}{c}\text { Both boys are } \\
\text { about equally bad }\end{array}$ & \\
\hline \multirow{2}{*}{ Action } & Correct & $9(37.5 \%)$ & $5(20.8 \%)$ & $10(41.7 \%)$ & 24 \\
& Wrong & $3(20.0 \%)$ & $4(26.7 \%)$ & $8(53.3 \%)$ & 15 \\
\cline { 2 - 5 } & Total & 12 & 9 & 18 & 39 \\
\hline \multirow{2}{*}{ Inaction } & Correct & $9(37.5 \%)$ & $7(29.2 \%)$ & $8(33.3 \%)$ & 24 \\
& Wrong & $4(26.7 \%)$ & $4(26.7 \%)$ & $7(46.7 \%)$ & 15 \\
\cline { 2 - 5 } & Total & 13 & 11 & 15 & 39 \\
\hline
\end{tabular}

15 participants gave correct answers to the mental state question but made wrong answers to the moral judgment question, whereas only four showed the reverse pattern (McNemar's test: $\chi^{2}(1)=6.37, p<.05$ ). These results indicate that children can understand mental states before they can make appropriate moral judgments.

\section{Consistency of Answers to Moral Judgment Questions Within the Two Tasks}

Table 3 shows the response patterns to the moral judgment questions in the two tasks. The three patterns of consistent judgments (both "correct", both "opposite", and both "both boys are about equally bad") were 69.2\% (27/39). Overall, there was a strong consistency in participants' judgments, especially, among those who responded that "both boys are about equally bad" in the action task, 78.9\% (15/19) also gave the same answer in the inaction task.

\section{Justification Questions}

Based on Hayashi (2007), children's justifications for the moral judgment questions were coded into the following three categories: "Describing mental states", "Not describing mental states", and "Nonsense or No response." Describing mental states was coded when the main character's (boy's) mental state was presented. For example, in the case of a correct answer to the moral judgment question, "Because the boy scribbled the paper despite knowing that the paper belonged to the girl." Not describing mental states was coded when the main character's mental state was not presented. For example, in the case of a wrong answer, "Because both boys scribbled away." Nonsense or No response was coded when nonsensical information was mentioned or when participants said nothing. Participant's justifications presented in Table 4 show that children's justifications depended on the response for the moral judgment questions $\left(\chi^{2}(2)=13.62, p<.01\right.$, for the action task; $\chi^{2}(2)=7.32, p<.05$, for the inaction task). Participants tend to refer to 
Table 3. Response Patterns to the Moral Judgment Question Within the Two Tasks

\begin{tabular}{clcccc}
\hline & & \multicolumn{4}{c}{ Inaction } \\
\cline { 3 - 6 } & & Correct & Opposite & $\begin{array}{c}\text { Both boys are } \\
\text { about equally bad }\end{array}$ & Total \\
\hline \multirow{2}{*}{ Action } & Correct & $7(63.6 \%)$ & $4(36.4 \%)$ & $0(0 \%)$ & 11 \\
& $\begin{array}{l}\text { Opposite } \\
\text { Both boys are } \\
\text { about equally bad }\end{array}$ & $2(10.5 \%)$ & $2(10.5 \%)$ & $15(78.9 \%)$ & 19 \\
\cline { 2 - 6 } & \multicolumn{1}{c}{ Total } & 13 & 11 & 15 & 39 \\
\hline
\end{tabular}

Table 4. Justifications on the Two Tasks

\begin{tabular}{cccccc}
\hline \multirow{2}{*}{ Act type } & Moral judgment & \multicolumn{4}{c}{ Justifications } \\
\cline { 3 - 6 } & question & $\begin{array}{c}\text { Describing } \\
\text { mental states }\end{array}$ & $\begin{array}{c}\text { Not describing } \\
\text { mental states }\end{array}$ & $\begin{array}{c}\text { Nonsense or } \\
\text { No response }\end{array}$ & Total \\
\hline \multirow{2}{*}{ Action } & Correct & $5(41.7 \%)$ & $4(33.3 \%)$ & $3(25.0 \%)$ & 12 \\
& Wrong & $0(0 \%)$ & $10(37.0 \%)$ & $17(63.0 \%)$ & 27 \\
\cline { 2 - 6 } Inaction & Total & 5 & 14 & 20 & 39 \\
& Correct & $3(23.1 \%)$ & $6(46.2 \%)$ & $4(30.7 \%)$ & 26 \\
\cline { 2 - 6 } & Wrong & $0(0 \%)$ & $11(42.3 \%)$ & $15(57.7 \%)$ & 39 \\
\hline
\end{tabular}

mental states when the moral judgment questions were answered correctly. In contrast, participants did not refer to the mental states, offered nonsensical information, or said nothing when the moral judgment questions were answered wrongly.

\section{DISCUSSION}

The main purpose was to examine whether a developmental difference existed in children's ability to recognize acts of commission and omission. As shown in Table 1, for the mental state questions, the percentages of correct answers were higher in older children than in younger children, but did not differ between the action and the inaction tasks for children in all three age groups. These results indicate that there is no difference in the degree of difficulty in understanding both two tasks. As shown in Table 1 and Table 4, for the moral judgment questions and the justification questions, the percentages of correct answers did not differ between the action and the inaction tasks for children in 
all three age groups. These results also indicate that there is no developmental difference in recognizing commission and omission. Humans usually show omission bias, meaning that they judge acts of commission to be worse than omission (e.g., Haidt \& Baron, 1996; Ritov \& Baron, 1990; Spranca et al., 1991). These findings suggest that there is a cognitive difference in moral judgments about acts of commission and omission, but no developmental difference in moral judgments about them.

Children's actions that cause bad outcomes may be more chastised than their inactions, because acts of commission are usually apparent. Hence, children should be exposed more to situations that demand the learning of commission than omission. Nevertheless, there is no developmental difference in recognizing them. This finding implies that evaluating the acts related to mental states may be independent of the act type. In fact, philosophers such as Bennett (1981) suggest that the distinction between commission and omission by itself is irrelevant in moral judgments. The distinction only influences our judgments when we must directly compare them and make moral judgments. Omission bias (e.g., Spranca et al., 1991) occurs in such a case.

The other purpose of the present study was to check that children's moral judgments of both types of acts required their understanding of mental states. As shown in Table 2, children were more likely to give correct answers to the mental state question but made wrong answers to the moral judgment question than the reverse pattern. These results suggest that children can understand mental states before they can make moral judgments. Taken together, whether in the case of commission or omission, moral judgments required an understanding of mental states. But, in contrast to the findings of elementary school children (Hayashi, 2007), a strong relationship may not exist between young children due to the low percentages of correct answers for moral judgment questions for all three age groups. If we regard these questions as having three choices, then the percentages of correct responses approach chance levels. However, a large majority of them made consistent moral judgments within the two tasks (see Table 3). Therefore, these percentages indicate that younger children generally have difficulty recognizing commission and omission on the basis of knowledge and ignorance.

Previous studies demonstrated that children understand first-order mental states by approximately the age of 4 to 5 years (e.g., Goushiki, 2000; Wellman et al., 2001), and evaluate behavior based on the mental states such as intention at similar ages (e.g., Nelson, 1980). These findings indicate that children can evaluate behavior based on intention soon after they understand first-order mental states. By contrast, children do not seem to be able to make the same moral judgments based on the knowledge as adults until a later age. These findings would also be important for moral education. For example, parents and teachers must exercise caution when scolding a child who is too young to make appropriate moral judgments. If the situation requires understanding knowledge rather than intention, young children will have difficulty.

Several issues remain pertaining to our methods. The first issue is that the percentages of correct answers to the mental state questions were low at the age of 5 years. Meta-analysis showed that Japanese children understand first-order beliefs at around the age of 5 years (e.g., Goushiki, 2000; Wellman et al., 2001). Furthermore, some research 
has suggested that children understand knowledge (ignorance) before beliefs (e.g., Hogrefe, Wimmer, \& Perner, 1986). Therefore, the low performance of the mental states questions and the moral questions might mean that the information-processing demands in the present study were high for participants. Further studies should consider minimizing the information-processing demands.

The second issue is that further studies should consider not only knowledge as mental states but also intention. In the present tasks, the story in which the boy knew an important fact can be further divided into two cases by considering the degree of intention: with or without malice. If children think that the boy's action/inaction in this story was with malice, then the differences in their judgment of the degree of the boy's badness between two stories would have been bigger than if children think that the boy's action/inaction in this story was without malice. If so, it would have been easier to distinguish the two stories. The degree that malice facilitates the intelligibility of tasks may differ between commission and omission.

\section{REFERENCES}

Baird, J. A., \& Astington, J. W. 2004. The role of mental state understanding in the development of moral cognition and moral action. New Directions for Child and Adolescent Development, 103, 37-49.

Baron, J., Granato, L., Spranca, M., \& Teubal, E. 1993. Decision-making biases in children and early adolescents: Exploratory studies. Merrill-Palmer Quarterly, 39, 22-46.

Bennett, J. 1981. Morality and consequences. In S. M. McMurrin (Ed.), The Tanner lectures on human values (vol. 2, pp. 45-116). Salt Lake City: University of Utah Press.

Farnill, D. 1974. The effects of social-judgment set on children's use of intent information. Journal of Personality, 42, 276-289.

Goushiki, T. 2000. The meta-analysis of correct answer rates in the memory question of self-belief-change tasks with Quantification Theory Type 1. Japanese Psychological Review, 43, 456-475. (In Japanese with English abstract)

Haidt, J., \& Baron, J. 1996. Social roles and the moral judgement of acts and omissions. European Journal of Social Psychology, 26, 201-218.

Hayashi, H. 2007. Children's moral judgments of commission and omission based on their understanding of second-order mental states. Japanese Psychological Research, 49, 261-274.

Hogrefe, G. J., Wimmer, H., \& Perner, J. 1986. Ignorance versus false belief: A developmental lag in attribution of epistemic states. Child Development, 57, 567-582.

Karniol, R. 1978. Children's use of intention cues in evaluating behavior. Psychological Bulletin, 85, 76-85.

Keasey, C. B. 1977. Children's developing awareness and usage of intentionality and motives." In C. B. Keasey (Ed.), Nebraska symposium on motivation (pp. 219-260). Lincoln: University of Nebraska Press.

Mant, C. M., \& Perner, J. 1988. The child's understanding of commitment. Developmental Psychology, 24, 343-351.

Nelson, S. A. 1980. Factors influencing young children's use of motives and outcomes as moral criteria. Child Development, 51, 823-829.

Nelson-Le Gall, S. A. 1985. Motive-outcome matching and outcome foreseeability: Effects on attribution of intentionality and moral judgments. Developmental Psychology, 21, 332-337.

Piaget, J. 1932. The moral judgment of the child. New York: Free Press.

Perner, J., \& Wimmer, H. 1985. "John thinks that Mary thinks that...": Attribution of second-order beliefs by 5- to 10-year-old children. Journal of Experimental Child Psychology, 39, 437-471.

Ritov, I., \& Baron, J. 1990. Reluctance to vaccinate: Omission bias and ambiguity. Journal of Behavioral Decision Making, 3, 263-277. 
Spranca, M., Minsk, E., \& Baron, J. 1991. Omission and commission in judgment and choice. Journal of Experimental Social Psychology, 27, 76-105.

Wellman, H. M., Cross, D., \& Watson, J. 2001. Meta-analysis of theory-of-mind development: The truth about false belief. Child Development, 72, 655-684.

Yuill, N., \& Perner, J. 1987. Exceptions to mutual trust: Children's use of second-order beliefs in responsibility attribution. International Journal of Behavioral Development, 10, 207-223.

(Manuscript received July 14, 2008, Revision accepted June 15, 2009) 